\title{
Greetings from the New Editor
}

\author{
Michael Diringer ${ }^{1}$
}

Published online: 22 January 2018

(C) Springer Science+Business Media, LLC, part of Springer Nature 2018

I am excited and grateful to have been selected to be the second Editor-in-Chief of Neurocritical Care. It is a bit daunting to accept the reins from someone who had the vision to create this journal, the drive to bring it to fruition, and the dedication and hard work needed to manage it. My personal measure of success will be, to borrow from Ralph Waldo Emerson, for the journal to win the respect of intelligent people.

Moving forward, I would like to share my thoughts on the role the journal plays and how it will evolve. I envision that, as the official journal of the Neurocritical Care Society, Neurocritical Care will be the primary source for presenting scientific investigations, critical analysis, and informed discussion of issues addressing the care of the patients we serve. It will serve as an international forum for the exchange of ideas, information, and strategies that address the major challenges facing our field. Readers will turn to the journal to inform immediate care decisions, deepen knowledge, and advance further scientific discovery. Finally, it will take an active role in educating its readers about how to interpret the literature.

The journal serves several constituencies. First and foremost its readers, especially the members of the Neurocritical Care Society, followed closely by its authors. Others include our patients, the scientific community and the publisher. Each has different interests, goals and motivations for interacting with the journal that are not always in concert. Readers seek fresh and exciting information that advances the care of their patients and to better understand how to interpret the material they are being presented. Authors seek an easy submission and review process, strive to get their work reported in a prestigious journal, and demonstrate their academic productivity. Our patients and the scientific community demand rigor and integrity to ensure that high quality work is presented.

Michael Diringer

diringerm@wustl.edu

1 Department of Neurology, Washington University in Saint Louis, St Louis, MO, USA
My goal is to achieve some balance between these competing goals. In this age of rating scales, the Impact Factor has been the go-to metric for assessing journals. Yet it hardly captures the range of factors that make a journal successful and is subject to manipulation. It discourages publishing papers from early career investigators, along with educational and other material that is of interest to the readers but not necessarily citable. Other scales are being developed that may broaden the scope of evaluation; time will tell. However, as the journal evolves, my focus will be serving its constituencies rather than a rating scale.

Over the next several issues, a number of changes will be implemented. In this issue the editorial board has been refreshed, article types and requirements revised, and the page layout modified. Soon the cover will have a new look. An article will be selected in each issue as a feature article. The education focus will include more commentaries on articles, discussions on how to interpret the literature, debate of current controversies, and news and updates from the Neurocritical Care Society.

Reviewers are the backbone of the peer review process. They volunteer their time and energy with no compensation. Without them, we could not function, yet no means of rewarding their efforts currently exists. As a first step in that direction, we will be awarding prizes to top reviewers and sending letters to each reviewer's employer acknowledging their hard work and urging that it be considered when evaluating their performance.

I look forward to being able to build upon the strong foundation laid by Dr. Wijdicks. Medicine and the medical literature are going through a period of enormous change, and I am grateful for and challenged by the opportunity to lead our journal during these interesting times. 